\title{
REPRODUCTIVE INDICATORS OF F1-F3 GENERATIONS OF SILKWORM OBTAINED UNDER POOR NUTRITIONAL CONDITION
}

\author{
Valiev Sayfiddin Tojiddinovich and Nasirillaev Bakhtiyor Ubaydullaevich \\ Scientific Research Institute of Sericulture 100169, Ipakchi 1, Tashkent, Uzbekistan \\ https://doi.org/10.35410/IJAEB.2021.5610
}

\begin{abstract}
Adaptation of silkworm to various unfavorable conditions is of great practical importance in the conditions of Uzbekistan. Because in Uzbekistan, in spring and summer seasons, various stress factors affect silkworm rearing. This article presents the results of the study on the response of 4 breeds and 2 new systems of mulberry silkworm to poor nutritional stress according to their reproductive traits.

According to the results of the experiment, the susceptibility of strains and systems of silkworm to poor feeding was clearly demonstrated in the physiological defect index in egg laying. On the three-year average indicators, in the comparative variant the proportion of physiologically defective eggs in the laying was $0.6-1.5 \%$, while in the experimental variant made in the condition of poor nutrition, this figure was slightly higher at $1.1-1.7 \%$. On this trait in breeding progeny of Ipakchi 1 and Ipakchi 2 breeds the physiological defect rate didn't exceed from 0.6$0.9 \%$ in unfovarble conditions. It means that these two breeds are more adaptable to unfovarble conditions.
\end{abstract}

Keywords: Silkworm, Egg, Cocoon, Food, Mulberry, Adaptation, Stress Factor.

\section{INTRODUCTION}

Today, the worldwide 22-24 million boxes of eggs of industrial hybrids and more than 100 thous. boxes of elite eggs of silkworm are produced annually. According to the data by International Sericulture Commission, $80.9 \%$ of produced raw silk comes from PRC, $16.5 \%$ from India, $1.2 \%$ from Uzbekistan and $1.4 \%$ from other countries. In different climatic conditions, the yield of cocoons from a box of silkworm varies around 50.0-85.0 kg. Under the influence of sharp and temperate natural climatic conditions, the variety of cocoons constitutes $50.0-80.0 \%$, the uniformity of cocoons by caliber is $60.0-90.0 \%$.

One of the most pressing problems in the silk industry today is the development of special selection methods that provide the adaptation and resistance of systems and breeds of mulberry silkworms to the nutritional deficiencies in breeding process and the creation of promising breeding systems and breeds of silkworm resistant to adverse conditions. In recent years, the bulk of industrial hybrid eggs of silkworm reared in the Republic are imported, and this figure is expected to gradually decrease from year to year. 
Therefore, it is necessary to establish in the breeding and seed enterprises of the Republic the production of new breeds of mulberry silkworms competitive in terms of high productivity and technological properties, as well as industrial hybrid eggs with their participation. It should be noted that as the technological performance of mulberry silkworms increases, their viability decreases, as evidenced by science. However, the selection has such a great potential that with its proper use it is possible to create silkworm breeds with high technological performance and are resistant to the sharp continental climatic conditions of our country and the stress factors that can occur during the rearing of silkworms.

Unlike other farm animals, mulberry silkworm must be reard under optimal hygrothermal and nutrient conditions, as changes in air temperature, humidity or feed quantity and quality can directly affect the final result of rearing. However, non-compliance with normal hygrothermal conditions in incubators, rearing facilities and cocoonery is observed, as well as unfavorable conditions such as frequent spring frosts or extreme heat during the period of silkworm rearing in the country, directly affect the process of silkworm rearing.

As a result, the number of silkworms decreases, productivity of produced cocoon doesn't meet the requirements, as well as the quality indicators and cocoon variety are noted to decrease sharply. In the countries with developed sericulture like PRC and India, 80-85 kgs of high quality cocoon yield per box is obtained today, out of which the rate of raw silk yield makes $41,0-42,0 \%$, while the metric number of fiber is noted to be higher than $3500 \mathrm{~m} / \mathrm{g}$. The main reason for such achievements is, firstly, properly organized and diligent selection-breeding work, which have been carried out continuously at every stage of the selection process and breeding work in research institutions and secondly, a strict follow to agrotechnical rules.

Silkworms respond to temperature changes at all stages of their development. In this regard, it is extremely important to study the extent to which temperature affects the eggs, larvae, pupa and butterflies of silkworms, as well as changes in the biological and technological characteristics of the next generation of cocoons. In particular, the preservation of the breeding potential of breeds and hybrids to some extent in unfavorable conditions is of great scientific and practical importance.

In order to study this problem, we got acquainted with the scientific work done in this direction in the scientific literature.

Mulberry silkworms are extremely sensitive to the external condition due to the fact that they feed only on the same food, namely mulberry leaves. It has been noted that in years when the weather is very unfavorable during the silkworm rearing seasons, not only productivity traits but also the genetic parameters of selection populations change [1]. In particular, in the unfavorable conditions of silkworm rearing, a significant change in the coefficients of variation and correlation of silk productivity and fertility traits of the large-cocoon Marvarid breed was observed. As a result of the process of rearing worms in unfavorable environmental conditions, the efficiency of selection decreases. 
Without a favorable external environment for silkworms, their growth and development, producing the next generation, and productivity characteristics may decline [2]. This means that the growth and development of farm animals, including silkworms, as well as productivity indicators can be controlled by changing environmental factors to a certain extent.

Studies in Uzbekistan have shown that it is possible to control changes in the productivity characteristics of silkworms under the external environment $[3,4]$.

It was found that an increase in incubation temperature to $29-32^{\circ} \mathrm{C}$ led to an imbalance in embryonic development in the egg, a sharp decrease in worm vitality due to a moisture reduction in the eggs, the larvae became sensitive to diseases and got infected, cocoon yield and quality decreased accordingly [5].

It was also determined that the temperature in incubation of silkworm eggs should be $24-25^{\circ} \mathrm{C}$ and humidity $75-80 \%$, and frequent changes in air temperature in the incubator were noted to have a negative impact on embryonic development [6]. In their experiments, the authors reported that a rise in temperature in incubation to $26^{\circ} \mathrm{C}$ reduced worm hatching by $86 \%$, at $28^{\circ} \mathrm{C}$ by $82 \%$, at $30^{\circ} \mathrm{C}$ by $79 \%$, and at $32^{\circ} \mathrm{C}$ by $76 \%$.

The viability of silkworms depends on the temperature created for them, and it has been proven that when silkworms are reared at low temperatures $\left(20-21^{\circ} \mathrm{C}\right)$ their viability makes $80-83 \%$ and at moderate temperatures $\left(25-26^{\circ} \mathrm{C}\right) 89-92 \%$ [7].

Based on the research carried out, during cocoon spinning period of silkworm the temperature $25-26^{\circ} \mathrm{C}$ was found to be optimal in cocoonery [8]. If the temperature is $28-29^{\circ} \mathrm{C}$ or higher in cocoonery, then the cocoon spinning decreases by $2-3$ percent. Considering the aforementioned data it has been reported that it is expedient to maintain a normal temperature and humidity in the cocoonery, given the high impact of environmental factors during the cocooning.

Experiments in Bulgaria showed temperature and relative humidity limits according to the silkworm instars [9]. It is very interesting to get acquainted with the moderate regimes of silkworm rearing in India, where the air temperature is extremely high. Therefore, in India, it is recommended that young silkworms be fed at a temperature of $26-28^{\circ} \mathrm{C}$, humidity of $80-85 \%$, while adults at a temperature of $23-24^{\circ} \mathrm{C}, 70-75 \%$ humidity [10]. According to the authors' report, this temperature and humidity regime used in silkworm rearing provides a much higher cocoon yield in this country,

In the process of silkworm rearing with artificial feeding, light has been shown to play an important role in the growth and development of silkworms, and it has been argued that this factor is also important in cocoon spinning [11].

The experiments conducted in Japan showed that an increase in relative humidity of air in cocoonery during the silkworm rearing affected negatively to cocoon reeling [12]. 
Vol. 06, No. 01; 2021

ISSN: $2456-8643$

Uzbek scientists have created in recent years new industrial hybrids adaptable to different climatic conditions of the country $[13,14,15,16,17]$. The response of these hybrids to various stresses was fond to be different. Furthermore, recommendations have been given on effective use of sex-regulation of silkworm to increase resistance of silkworm to unfavorable conditions.

\section{MATERIALS AND METHODS}

In order to study adaptability features of silkworms to limited conditions of paratypic factors such as feed amount, air temperature and humidity levels in silkworm rearing period, the breeds Guzal and Marvarid, the systems Line 27, Line 28 that were created in "Silkworm breeding" laboratory of Sericulture research institute, and Ipakchi 1, Ipakchi 2 breeds created in "Silkworm genetics and selection" laboratory were used in the experiments. Silkworm rearing practices in experiments were carried out in spring season of 2018-2020 in special selection and ecological cocoonery and rearing facilities of Sericulture research institute. Norm-limited unfavorable conditions were created artificially.

Creating artificial unfavorable conditions for silkworm rearing. For conducting experiments, 3 different variants were formed under unfavorable conditions and an artificial stress factor was created.

The first variant: To reduce the amount of nutrition given to worms by $50 \%$. For this, the larva in the experimental variant were cared for according to agronomic rules until the $4^{\text {th }}$ instar by giving the full amount of food by norm, but in the fourth and fifth instars of silkworm the food was reduced by $50 \%$.

The second variant: The silkworms were reared with optimal nutrition norm until the 4th instar under normal hygrothermal conditions, i.e. $26-27^{\circ} \mathrm{C}$ temperature and $75-80 \%$ relative humidity, while in the fourth and fifth instars the rearing was continued at natural (unheated) temperature in the cocoonery, where moisture was not provided, not followed to temperature and humidity norms.

The third variant: The silkworms were reared dense in the cocoonery where the rearing area was less by $50 \%$ than the allowed area by agronomic rules.

During the experiments, the silkworms were reared on 3 different variants in order to determine the degree of change in the indicators of the major farm-valuable traits of mulberry silkworm breeds and systems under artificially created adverse stress conditions. For the purpose of conducting experiments, a mixture of 30-40 initial egg samples of selected breeds was prepared. Reproductive traits of breeds and systems were identified and analyzed during the fall and winter seasons prior to the preparation of egg stocks mixtures. In this case, the eggs laid by each female moth were counted individually, weighed on a torsion balance and the normal number of eggs in the stock, their weight, and the weight of one egg, as well as physiological defect index were determined. 
To determine the vitality (hatching) rate of eggs in egg mixtures, 100 egg samples were taken from each breed and system eggs in 4 replications and incubated at a temperature of $24-25^{\circ} \mathrm{C}$ and a relative humidity of $80-85 \%$. At the end of the incubation, the number of not hatched eggs was determined after the mass hatching and the percentage of hatched eggs was calculated.

The hatched larva from the egg mixtures of the breeds and systems were transferred and fed. At their initial instars the worms were reared under normal hygrothermal conditions. On the first day of the $2^{\text {nd }}$ instar, the larva for each variant were counted by 250 pieces in 4 replications.

The larva in 3 different artificially created experimental variants as well as in the comparative variant were reared separately. When they spinned the cocoon, their viability and the percentage of worm disease were determined. For this, the silkworms in the replications were collected 7 days after the start of mass cocoon spinning, and the number of healthy, deaf, double, and black cocoons was determined. The disease percentage was calculated by determining the viability rate of the larva through identifying the proportion of healthy cocoons from the number of worms counted on the first day of the $2^{\text {nd }}$ instar and the proportion of deaf cocoons within the healthy cocoons. The productivity of the cocoons was determined by weighing 15 우 $15 \hat{0}$ cocoons from each replication on an electronic scale. At the same time, the weight of the cocoons, the weight of the cocoon shell and the average indicators of silkiness traits were determined according to the variants.

\section{RESULTS AND DISCUSSION}

A group of scientists led by B.U.Nasirillaev has developed new effective selection and breeding methods aimed at maximizing the productivity and technological performance of mulberry silkworms, which are widely used in mulberry silkworm selection and breeding practices. However, scientific research identifying adaptation properties to adverse stress conditions that can often be encountered in the production of a selectional population of mulberry silkworm and their use in selection-breeding practices have been somewhat neglected.

The scientific significance of this research is that the response of existing breeds and hybrids of silkworms to stress factors has not been studied in depth since, and the differentiation and selection of adaptive genes in silkworm body are both a practical and theoretical innovation for silkworm genetics and selection.

Based on the abovementioned comments, it can be said that one of the current directions of silkworm genetics and selection is to create the breeds resistant and adaptable to various stressors during the rearing period, and to the specific climatic conditions of the Republic, to adapt the breeds and systems with the finest fiber to changeable conditions.

Great work is being done in the republic to establish the silkworm rearing on the basis of strict agro-technical rules. However, unfortunately, there are cases when in incubators and cocoonery normal hygrothermal conditions are not always provided in the production. In addition, unfavorable conditions, such as frequent spring frosts or sudden warming of the air in the territory of the republic during the rearing of silkworms, directly affect the process of worm care. 
As a result, the number of worms is reduced, the yield of cocoon is not at the required level, and at the same time there is a sharp decline in the quality and variety of cocoons. One of the current problems of silkworm egg production in our country is to provide the silkworm egg industry of the country with new high-yielding, high-tech breeds by increasing the resistance of purebred breeds and systems that make up our local hybrids to nutritional deficiencies and their adaptive properties in the population.

In the experiments conducted in 2018-2020, Guzal, Marvarid, Ipakchi 1, Ipakchi 2 breeds and Line 27 and Line 28 sytems were reared under 3 artificial stress conditions. According to the varaints in which the breeds and systems were reared under poor diet condition, total $1065 \mathrm{egg}$ stocks were prepared in 2019. In January-February 2020, a complete analysis of the reproductive traits of these egg stocks was carried out to determine the number of eggs in the egg stock, the weight of these eggs, the weight of one egg and the physiological defect indicators. As a comparative variant was taken the population of each breed and system that was reared in optimal hygrothermal conditions by following the rules of agro-technical rules.

Data on the extent to which the reproductive characteristics of the population of breeds and systems reared over three generations under conditions of poor diet have changed are given in Tables 1-3.

Table 1: Reproductive indicators of $F_{1}-F_{3}$ generations of Marvarid and Guzal breeds reared in poor diet condition ( in 2018-2020)

\begin{tabular}{|c|c|c|c|c|c|c|c|}
\hline $\begin{array}{c}\text { Years of } \\
\text { experiment }\end{array}$ & $\begin{array}{c}\text { Analyzed } \\
\text { egg stocks, } \\
\text { pes }\end{array}$ & $\begin{array}{c}\text { Number of } \\
\text { egg in a } \\
\text { stock } \\
\bar{X} \pm S \bar{x} \\
\text { pcs }\end{array}$ & $\begin{array}{l}\mathrm{C}_{\mathrm{v}}, \\
\%\end{array}$ & $\begin{array}{l}\text { Weight of } \\
\text { eggs in a } \\
\text { stock } \\
\bar{X} \pm \mathrm{S} \bar{x}, \mathrm{mg}\end{array}$ & $\begin{array}{l}C_{v}, \\
\%\end{array}$ & $\begin{array}{c}\begin{array}{c}\text { Physiological } \\
\text { defect }\end{array} \\
\bar{X} \pm \mathrm{S} \bar{x}, \%\end{array}$ & $\mathrm{C}_{\mathrm{v}}, \%$ \\
\hline \multicolumn{8}{|c|}{ Marvarid (experiment) } \\
\hline 2018 & 30 & $741 \pm 17,0$ & 12,4 & $458 \pm 13,6$ & 16,0 & $1,0 \pm 0,1$ & 90,0 \\
\hline 2019 & 25 & $600 \pm 15,9$ & 13,3 & $377 \pm 9,4$ & 9,7 & $0,8 \pm 0,08$ & 51,3 \\
\hline 2020 & 49 & $740 \pm 12,1$ & 11,4 & $439 \pm 7,4$ & 11,9 & $1,6 \pm 0,2$ & 81,3 \\
\hline Average & 35 & 694 & 12,4 & 425 & 12,5 & 1,1 & 74,2 \\
\hline $\begin{array}{r}\text { Relati } \\
\text { compara }\end{array}$ & $\begin{array}{l}\text { to the } \\
\text { ve, } \% \%\end{array}$ & 88,2 & & 87,0 & & 179,4 & \\
\hline \multicolumn{8}{|c|}{ Marvarid (comparative) } \\
\hline 2018 & 50 & $838 \pm 10,6$ & 7,6 & $522 \pm 5,8$ & 7,7 & $0,5 \pm 0,07$ & 42,5 \\
\hline
\end{tabular}


International Journal of Agriculture, Environment and Bioresearch

Vol. 06, No. 01; 2021

ISSN: $2456-8643$

\begin{tabular}{|c|c|c|c|c|c|c|c|}
\hline 2019 & 32 & $776 \pm 16,8$ & 12,2 & $477 \pm 11,0$ & 13,0 & $0,8 \pm 0,13$ & 92,5 \\
\hline 2020 & 56 & $746 \pm 10,3$ & 10,4 & $465 \pm 7,9$ & 12,7 & $0,6 \pm 0,05$ & 73,3 \\
\hline Average & 46 & 787 & 10,1 & 488 & 11,1 & 0,6 & 69,4 \\
\hline \multicolumn{2}{|c|}{ The comparative, $\%$} & 100,0 & & 100,0 & & 100,0 & \\
\hline \multicolumn{8}{|c|}{ Guzal (experiment) } \\
\hline 2018 & 29 & $717 \pm 16,6$ & 11,8 & $434 \pm 11,5$ & 14,0 & $1,9 \pm 0,3$ & 89,0 \\
\hline 2019 & 45 & $612 \pm 11,2$ & 12,3 & $363 \pm 7,7$ & 14,1 & $1,2 \pm 0,19$ & 106,6 \\
\hline 2020 & 60 & $781 \pm 11,0$ & 10,9 & $462 \pm 6,5$ & 10,8 & $1,2 \pm 0,2$ & 89,7 \\
\hline Average & 45 & 703 & 11,7 & 420 & 13,0 & 1,4 & 95,1 \\
\hline $\begin{array}{r}\text { Rela } \\
\text { compa }\end{array}$ & $\begin{array}{l}\text { he } \\
\% \%\end{array}$ & 90,0 & & 88,2 & & 233,3 & \\
\hline \multicolumn{8}{|c|}{ Guzal (comparative) } \\
\hline 2018 & 50 & $829 \pm 9,8$ & 8,3 & $514 \pm 7,3$ & 9,9 & $0,8 \pm 1,42$ & 42,5 \\
\hline 2019 & 30 & $748 \pm 16,5$ & 12,0 & $459 \pm 11,8$ & 14,0 & $0,6 \pm 0,06$ & 56,6 \\
\hline 2020 & 60 & $767 \pm 10,3$ & 10,4 & $456 \pm 5,1$ & 8,7 & $0,5 \pm 0,09$ & 140,0 \\
\hline Average & 93 & 781 & 10,2 & 476 & 10,9 & 0,6 & 79,7 \\
\hline \multicolumn{2}{|c|}{ The comparative, \% } & 100,0 & & 100,0 & & 100,0 & \\
\hline
\end{tabular}

Table 2: Reproductive indicators of $F_{1}-F_{3}$ generations of Ipakchi 1 and Ipakchi 2 breeds reared in poor diet condition ( in 2018-2020)

\begin{tabular}{|c|c|c|c|c|c|c|c|}
\hline $\begin{array}{c}\text { Years of } \\
\text { experiment }\end{array}$ & $\begin{array}{c}\text { Analyzed } \\
\text { egg } \\
\text { stocks, } \\
\text { pcs }\end{array}$ & $\begin{array}{c}\text { Number of } \\
\text { egg in a } \\
\text { stock } \\
\bar{X} \pm \mathbf{S} \bar{x}, \mathbf{p c s}\end{array}$ & $\begin{array}{c}\mathbf{C}_{\mathrm{v}}, \\
\%\end{array}$ & $\begin{array}{c}\text { Weight of } \\
\text { eggs in a } \\
\text { stock } \\
\bar{X} \pm \mathbf{S} \bar{x}, \mathbf{m g}\end{array}$ & $\begin{array}{c}\mathbf{C}_{\mathrm{v}}, \\
\mathbf{\%}\end{array}$ & $\begin{array}{c}\text { Physiological } \\
\text { defect } \\
\bar{X} \pm \mathbf{S} \bar{x}, \%\end{array}$ & $\mathbf{C}_{\mathbf{v}}, \boldsymbol{\%}$ \\
\hline \multicolumn{7}{|c|}{ Ipakchi 1 (experiment) } \\
\hline 2018 & 30 & $595 \pm 16,6$ & 15,0 & $387 \pm 10,3$ & 14,0 & $2,4 \pm 0,5$ & 116 \\
\hline 2019 & 32 & $631 \pm 14,3$ & 12,8 & $372 \pm 9,1$ & 13,9 & $1,2 \pm 0,27$ & 128,3 \\
\hline
\end{tabular}


International Journal of Agriculture, Environment and Bioresearch

Vol. 06, No. 01; 2021

ISSN: $2456-8643$

\begin{tabular}{|c|c|c|c|c|c|c|c|}
\hline 2020 & 33 & $731 \pm 12,2$ & 13,5 & $415 \pm 10,4$ & 14,4 & $1,5 \pm 0,2$ & 86,0 \\
\hline Average & 32 & 652 & 13,8 & 391 & 14,1 & 1,7 & 110,1 \\
\hline \multicolumn{2}{|c|}{$\begin{array}{c}\text { Relative to the } \\
\text { comparative, } \% \%\end{array}$} & 91,2 & & $\mathbf{9 8 , 0}$ & & 784,6 & \\
\hline \multicolumn{8}{|c|}{ Ipakchi 1 (comparative) } \\
\hline 2018 & 40 & $700 \pm 12,9$ & 10,7 & $428 \pm 16,8$ & 9,4 & $0,7 \pm 0,05$ & 42,0 \\
\hline 2019 & 7 & $616 \pm 50,0$ & 21,5 & $362 \pm 32,5$ & 23,7 & $1,3 \pm 0,45$ & 92,3 \\
\hline 2020 & 27 & $718 \pm 9,3$ & 6,9 & $408 \pm 6,7$ & 8,5 & $1,9 \pm 0,5$ & 13,69 \\
\hline Average & 25 & 678 & 13 & 399 & 13,9 & 1,3 & 49,3 \\
\hline \multicolumn{2}{|c|}{ The comparative, $\%$} & 100,0 & & 100,0 & & 100,0 & \\
\hline \multicolumn{8}{|c|}{ Ipakchi 2 (experiment) } \\
\hline 2018 & 30 & $651 \pm 9,8$ & 8,2 & $386 \pm 15,0$ & 21,0 & $1,6 \pm 0,3$ & 10,6 \\
\hline 2019 & 42 & $642 \pm 13,4$ & 13,8 & $387 \pm 9,2$ & 15,4 & $1,2 \pm 0,09$ & 53,3 \\
\hline 2020 & 32 & $703 \pm 22,1$ & 17,8 & $410 \pm 13,5$ & 18,6 & $1,3 \pm 0,2$ & 20,7 \\
\hline Average & 35 & 665 & 13,3 & 394 & 18,3 & 1,4 & 28,2 \\
\hline \multicolumn{2}{|c|}{$\begin{array}{c}\text { Relative to the } \\
\text { comparative, } \% \%\end{array}$} & & & 93,8 & & 93,3 & \\
\hline \multicolumn{8}{|c|}{ Ipakchi 2 (comparative) } \\
\hline 2018 & 40 & $702 \pm 12,5$ & 12,0 & $412 \pm 19,3$ & 15,0 & $0,74 \pm 0,03$ & 39,0 \\
\hline 2019 & 14 & $721 \pm 18,8$ & 9,8 & $428 \pm 11,6$ & 10,0 & $2,8 \pm 1,23$ & 163,8 \\
\hline 2020 & 50 & $743 \pm 8,2$ & 7,8 & $419 \pm 4,5$ & 7,6 & $1,0 \pm 0,09$ & 70,0 \\
\hline Average & 35 & 722 & 9,9 & 420 & 10,9 & 1,5 & 90,9 \\
\hline \multicolumn{2}{|c|}{ The comparative, \% } & & & 100,0 & & 100,0 & \\
\hline
\end{tabular}

In tables 1-3, we can see that in some breeds the deficiency in the feeding of experimental variant differs significantly from the comparative variant in terms of fertility of silkworms. 
In the experiments conducted in 2020, it was proved in the indicators in table 1 that the response of populations of breeds and systems to adverse conditions is different on reproductive indicators. In particular, the experimental variants of the Guzal, Ipakhi 1 breeds and Line 27, Line 28 selection systems had significantly higher performance than the comparative variant.

In experimental variants, the number of eggs in a stock in Guzal breed was 781 pieces, in Ipakchi 1 breed 731 pieces, in Line 27 selection system 637 pieces, in Line 28 selection system 617 pieces, while in comparative variant this indicator in Guzal breed made 767 pieces, Ipakchi 1 breed 718 pieces, Line 27 selection system 531 pieces, Line 28 selection system 566 pieces.

The weight of egg stock in experimental variant in Guzal breed was $462 \mathrm{mg}$, Ipakchi 1 breed $415 \mathrm{mg}$, in Line 27 selection system $731 \mathrm{mg}$, Line 28 selection system $328 \mathrm{mg}$, while in comparative variant this indication was $456 \mathrm{mg}$ in Guzal breed, Ipakchi 1 breed $408 \mathrm{mg}$, Line 27 selectional system $293 \mathrm{mg}$, Line 28 system $295 \mathrm{mg}$.

In terms of the number of eggs in a stock, the lowest rate was observed in Marvarid and Ipakchi 2 breeds in experimental variant, 740-703 pieces, while in comparative variant 746-743 pieces respectively.

We can see a similar trend in the weight of the egg stock. Here, too, we can see that the indicators of Marvarid and Ipakchi 2 breeds in experimental variant are slightly lower than the comparative variant. Comparing the results in figures, the weight of egg stock in the experimental variant of these breeds was $439-410 \mathrm{mg}$, and in the comparative variant was 465$419 \mathrm{mg}$.

The highest result in terms of the superiority of the experimental variant over the comparative variant on the average of 3 years of experiments conducted during 2018-2020 was observed in the Line 27 selection system. In terms of the number of eggs in a stock, the advantage of the experimental variant over the comparative variant was $101.7 \%$, and in terms of the weight of the egg stock was $106.8 \%$.

The susceptibility of breeds and systems to poor diet was also evident in the physiological defect in egg stock. In the comparative variant, on a 3-year average indicators of the breeds and systems, the proportion of physiologically defective eggs in the stock was $0.6-1.5 \%$, while in the experimental variant reared in poor diet condition, this figure was slightly higher at $1.1-1.7 \%$.

Table 3: Reproductive indicators of $F_{1}-F_{3}$ generations of Line 27 and Line 28 selection systems reared in poor diet condition ( in 2018-2020)

\begin{tabular}{|c|c|c|c|c|c|c|c|}
\hline $\begin{array}{c}\text { Years of } \\
\text { experiment }\end{array}$ & $\begin{array}{c}\text { Analyzed } \\
\text { egg } \\
\text { stocks, } \\
\text { pcs }\end{array}$ & $\begin{array}{c}\text { Number of } \\
\text { egg in a } \\
\text { stock } \\
\bar{X} \pm \mathbf{S} \bar{x}, \mathbf{p c s}\end{array}$ & $\begin{array}{c}\mathrm{C}_{\mathrm{v}}, \\
\%\end{array}$ & $\begin{array}{c}\text { Weight of } \\
\text { eggs in a } \\
\text { stock } \\
\bar{X} \pm \mathbf{S} \bar{x}, \mathbf{m g}\end{array}$ & $\begin{array}{c}\mathrm{C}_{\mathrm{v}}, \\
\%\end{array}$ & $\begin{array}{c}\text { Physiological } \\
\text { defect }\end{array}$ & $\mathbf{C}_{\mathrm{v}}, \%$ \\
\hline
\end{tabular}


International Journal of Agriculture, Environment and Bioresearch

Vol. 06, No. 01; 2021

ISSN: $2456-8643$

\begin{tabular}{|c|c|c|c|c|c|c|c|}
\hline \multicolumn{8}{|c|}{ Line 27 (experiment) } \\
\hline 2018 & 31 & $535 \pm 10,9$ & 11,2 & $295 \pm 7,5$ & 14,0 & $1,8 \pm 0,1$ & 50,0 \\
\hline 2019 & 28 & $469 \pm 12,1$ & 13,7 & $282 \pm 9,5$ & 17,7 & $1,8 \pm 0,56$ & 163,8 \\
\hline 2020 & 59 & $637 \pm 6,6$ & 8,0 & $371 \pm 4,0$ & 8,3 & $1,5 \pm 0,2$ & 80,0 \\
\hline Average & 39 & 547 & 11,0 & 316 & $\mathbf{7 , 8}$ & 1,7 & 97,9 \\
\hline $\begin{array}{l}\text { Relati } \\
\text { compar }\end{array}$ & $\begin{array}{l}\text { the } \\
\% \%\end{array}$ & 101,7 & & 106,8 & & 242,8 & \\
\hline \multicolumn{8}{|c|}{ Line27 (comparative) } \\
\hline 2018 & 50 & $606 \pm 6,3$ & 7,3 & $333 \pm 4,4$ & 9,3 & $1,2 \pm 0,16$ & 52,5 \\
\hline 2019 & 35 & $476 \pm 8,3$ & 10,4 & $262 \pm 4,6$ & 10,5 & $0,5 \pm 0,06$ & 10,5 \\
\hline 2020 & 35 & $531 \pm 5,7$ & 6,3 & $293 \pm 3,9$ & 7,8 & $0,4 \pm 0,03$ & 41,3 \\
\hline Average & 40 & 538 & 8,0 & 296 & 9,2 & 0,7 & 34,8 \\
\hline The com & ve, $\%$ & 100,0 & & 100,0 & & 100,0 & \\
\hline \multicolumn{8}{|c|}{ Line 28 (experiment) } \\
\hline 2018 & 6 & $413 \pm 48,7$ & 28,0 & $203 \pm 23,7$ & 28,0 & $4,6 \pm 2,0$ & 10,4 \\
\hline 2019 & 12 & $377 \pm 13,6$ & 12,5 & $195 \pm 10,3$ & 18,3 & $1,9 \pm 0,37$ & 68,4 \\
\hline 2020 & 37 & $617 \pm 16,7$ & 16,4 & $328 \pm 12,3$ & 20,9 & $1,4 \pm 0,2$ & 89,2 \\
\hline Average & 18 & 469 & 18,9 & 242 & 22,4 & 1,2 & 56,0 \\
\hline $\begin{array}{r}\text { Relati } \\
\text { compar }\end{array}$ & $\begin{array}{l}\text { the } \\
\% \%\end{array}$ & 82,3 & & 82,9 & & 133,3 & \\
\hline \multicolumn{8}{|c|}{ Line 28 (comparative) } \\
\hline 2018 & 50 & $611 \pm 7,7$ & 8,9 & $310 \pm 4,5$ & 10,1 & $1,0 \pm 0,07$ & 45,0 \\
\hline 2019 & 36 & $532 \pm 7,4$ & 8,3 & $270 \pm 3,2$ & 7,1 & $1,1 \pm 0,13$ & 70,0 \\
\hline 2020 & 35 & $566 \pm 10,5$ & 10,9 & $295 \pm 4,9$ & 9,8 & $0,5 \pm 0,04$ & 42,4 \\
\hline Average & 40 & 570 & 9,4 & 292 & 9,0 & $\mathbf{0 , 9}$ & 52,5 \\
\hline \multicolumn{2}{|c|}{ The comparative, \%\% } & 100,0 & & 100,0 & & 100,0 & \\
\hline
\end{tabular}


On the number of eggs in a stock $P d=0,806-0,999$;

On the weight of eggs in a stock $P d=0,911-0,999$;

On physiological defect $P d=0,452-0,979$.

\section{CONCLUSIONS}

According to the results of three generations of experiments, it was found that the normative reaction of mulberry silkworms of different breeds and systems differing from each other in alternative traits to paratypical factors of the external environment is at different levels.

In the third generation of populations of selection breeds and systems, the rate of change of fertility indicators under unfavorable conditions was determined at the level of the comparable population or higher than the comparator. The zoned large-cocoon Guzal, Ipakchi 1 breeds and Line 27, Line 28 systems have been proven to retain their potential even in adverse conditions.

The susceptibility of breeds and systems to fod deficiency was observed in the physiological defect index in egg stock. According to a 3-year average rate of breeds and systems, in the comparative variant, the proportion of physiologically defective eggs in the stock was $0.6-1.5 \%$, while in the experimental variant reared in poor diet condition, this figure was slightly higher at $1.1-1.7 \%$. In the second generation of Ipakchi 1 and Ipakchi 2 breeds on this trait, even under unfavorable conditions, the physiological defect rate did not exceed 0.6-0.9\%.

\section{REFERENCES}

Nasirillaev B.U., Lejenko S.S. Change in correlations between productive and reproductive traits depending on environmental conditions. Uzbek Biological Journal, Tashkent, (2003). No 3-4, pp. 96-98.

Nasirillaev U.N., Jumanov U. Advice to cocoon producers. "Mekhnat" published house, (1992). Khomidy Kh.S., Yuldashev Sh. The influence of the nutritional quality of the mulberry leaf on the biological parameters of the silkworm cocoons. Ipak, Tashkent, (2000). No 2, pp.8-10.

Khomidy Kh.S., Umarov Sh.R. The study of the influence of the nutritional quality of the mulberry leaf on the biological parameters of the silkworm cocoons. Ipak, Collection: Scientific bases of the development of Uzbek sericulture. Tashkent, (2001). pp.60-64.

Khomidy Kh.S. Changes in the nutritional quality of a mulberry leaf by growing seasons and its effect on the physiological and biochemical state, productivity and quality of silkworm cocoons. Tashkent, Fan, (2004). pp. 215-226.

Nasirillaev U.N., Umarov Sh.R. Cocoon yield depends on incubatory. Zooveterinary, Tashkent, (2009). No 4. pp. 6-7.

Parpiev B.A. The influence of environmental factors on physiological processes in the silkworm. Works of CARIS, Tashkent, (1976) $.9^{\text {th }}$ edition. pp.97-104.

Akhmedov N.A., Abdurakhmonov A. Preparing and processing cocoons. Tashkent, Ukituvchi, (2006). pp. 15-18.

Petkov N.I., Petrov A.I., Yankov A.A. Basic principles and organization of selection-breeding practices with mulberry silkworm. Zemizdat, Sofiya, (1979). pp. 23-28. 
Vol. 06, No. 01; 2021

ISSN: $2456-8643$

Ullal S.R., Marasimhanns M.N. Handbook of practical sericulture. Central silk Board, Bombey, (1981). pp.118-119.

Takamiya K., Kinoshita D., Kato M. Influence of lighting conditions on the growth and development of silkworms on artificial feed. Bikhonsansigfkudzaessi, (1982). T. 51, No 1, pp. 14-15.

Kavaguchi T. A simplified way to regulate humidity during cocooning. Silk, Tashkent, (1989). No 9. 69 p.

Umarov Sh.R., Nasirillaev B.U., Jumaniyozov M.Sh., Rajabov N.O., Batirova A.N., Khudjamatov S.Kh. Embryonic and postembryonic viability of second generation $\left(\mathrm{F}_{1}\right)$ of silkworm breeds and lines obtained under unfavorable stressful conditions. International journal of scientific technology research, India, (2020). No 3. pp. 863-866.

Nasirillaev B.U., Jumaniyozov M.Sh., Khudjamatov S.Kh., Halilova M.F. Genetical basis for the breeding of sex-regulated Bombyx mori L. silkworm breeds and hybrids. Journal of Critical Reviews, India. (2020). Vol. 7, Issue 3, pp. 1124-1129.

Lejenko S.S., Nasirillaev B.U., Abdikodirov M.A. Development of a method for detecting embryonic sex-linked Lethals of the silkworm Bombyx MoriL. International Journal of Trend in Scientific Research and Development, (2020). No 5, pp. 1532-1538.

Navruzov S.N., Rajabov N.O., Khudayberdiyeva U.S. Selection of female silkworm moths conducive for increasing silk productivity. International Journal of Research Culture Society, (2020). Volume 4, Issue 2, pp. 9-11.

Rajabov N.O., Fozilova Kh.P. The impacts new mullberry varieties on the silk worm productivity and their technological indicators. International Journal for Innovative Research in Multidisciplinary Field, (2018). Volume 4, Issue 6, pp. 19-23.

Rakhmonberdiev V.K., Rajabov N.O., Fozilova Kh.P. Growing one and half year-old seedlings of mulberry hybrids in the condition of Kashkadarya region. EPRA International Journal of Research and Development (IJRD), (2020). Volume 5, Issue 1, pp. 2019-222. https://doi.org/10.36713/epra3956 